\title{
Pellets de trigo e soja produzidos por extrusão
}

\author{
Wheat and soybean pellets produced by extrusion-cooking
}

\author{
Sin Huei WANG ${ }^{1 *}$, Talita Pimenta do NASCIMENTO ${ }^{1}$, Gláucia da Silva BATISTA \\ Samantha Piler de MENESES ${ }^{1}$, José Luis Ramírez ASCHERI ${ }^{2}$
}

\begin{abstract}
Resumo
A mistura de trigo e soja representa uma importante fonte calórico-protéica com proteínas de boa qualidade. Apesar disso, a utilização da soja como ingrediente tem sido limitada pelo seu sabor de feijão cru (beany flavor), o qual é melhorado pelo processo de extrusão. Foram estudados os efeitos de umidade da mistura, Temperatura de Barril (TB) e Velocidade de Rotação de Parafuso (VRP, No 5) do extrusor no Índice de Expansão (IE), no Índice de Solubilidade em Água (ISA) e nas características sensoriais de pellets produzidos com mistura de trigo e soja (90:10), objetivando a otimização deste processo para a obtenção de pellets fritos com melhores qualidades sensoriais. A farinha mista crua foi extrusada em 2 umidades (32 e 35\%), $4 \mathrm{~TB}\left(60\right.$ a $\left.90^{\circ} \mathrm{C}\right)$ e $4 \mathrm{VRP}(60$ a $150 \mathrm{rpm})$, totalizando 32 tratamentos. O pellet frito, preparado com a farinha mista com $32 \%$ de umidade e extrusada em $60 \mathrm{rpm}$ a $80^{\circ} \mathrm{C}$, apresentou o maior IE e as melhores qualidades sensoriais (aparência, sabor e textura), sendo preferido pela equipe de provadores não treinados, tanto com sabor de bacon como com sabor de queijo.

Palavras-chave: produto extrusado; farinha de trigo-soja; snack de $3^{a}$ geração.
\end{abstract}

\begin{abstract}
The mixture of wheat with soybean represents an important calorie-protein source with good protein quality. In spite of this, the use of soybeans as an ingredient has been limited by their beany flavor, which is improved by the extrusion process. Effects of mixture moisture, Barrel Temperature (BT) and Screw-Speed (SS, No 5) on Expansion Index (EI), Water Solubility Index (WSI) and sensory characteristics of pellets produced with a wheat-soybean (90:10) mixture were studied, in order to optimize this process for obtaining fried pellets with better sensory qualities. Raw mixed flour was extruded at two moisture contents (32 and 35\%), four BT ( 60 to $90{ }^{\circ} \mathrm{C}$ ) and four SS (60 to $150 \mathrm{rpm}$ ), totalizing 32 treatments. The fried pellets, prepared with the mixed flour with $32 \%$ moisture and extruded at $60 \mathrm{rpm}$ and $80{ }^{\circ} \mathrm{C}$, presented the greatest EI and the best sensory qualities (appearance, flavor and texture), being the most preferred by the untrained consumer-type panelists, both with bacon flavor, as with cheese flavor.
\end{abstract}

Keywords: extrusion-cooked product; wheat-soybean flour; $3^{\text {rd }}$ generation snack.

\section{Introdução}

Snacks de terceira geração têm recebido crescente atenção nos últimos anos, devido a suas diversas formas e texturas, as quais podem ser obtidas a partir dos produtos "vítreos" intermediários, também chamados de pellets (GIMENO; MORARU; KOKINI, 2004).

Em geral, o processo de extrusão resulta em gelatinização do amido, desnaturação das proteínas, formação de complexos entre amido e lipídios e entre proteínas e lipídios (MERCIER et al., 1980). Estas mudanças, segundo Chen et al. (1991), influenciam na aparência, aroma, sabor e textura dos produtos extrusados.

O volume de expansão é o indicador de qualidade primário associado com a crocância, a dureza e a mastigabilidade de produtos extrusados expandidos (CHEN et al., 1991). Alguns trabalhos têm avaliado o papel de variáveis do processo de extrusão como Temperatura de Barril (TB), configuração de parafuso, tamanho e forma da matriz, velocidade de parafuso e conteúdo de umidade, sobre expansão de produtos contendo farinha ou amido de milho (CHINNASWAMY; HANNA, 1988; OWUSU-ANSAH; VOORT; STANLEY, 1983). Características das matérias-primas, tais como conteúdos de proteínas, lipídios e amido, e suas composições, podem também afetar o volume de expansão dos produtos extrusados (CHINNASWAMY; HANNA, 1988; LAUNAY; LISCH, 1983).

A soja tem sido reconhecida como excelente fonte para melhorar o perfil de aminoácidos e aumentar conteúdos totais de proteína em produtos de trigo (CABALLERO-CÓRDOBA; WANG; SGARBIERI, 1994).

Desta forma, o presente trabalho teve por objetivo estudar os efeitos de parâmetros do processo de extrusão, como a velocidade de rotação de parafuso, a TB e a umidade da mistura, no índice de expansão, no índice de solubilidade em água e nas características sensoriais de pellets produzidos com mistura de trigo e soja (90:10), visando a otimização deste processo para a obtenção de pellets fritos com boas qualidades sensoriais.

Recebido para publicação em 28/3/2007

Aceito para publicação em 13/8/2007 (002430)

Departamento de Economia Doméstica, Universidade Federal Rural do Rio de Janeiro - UFRRJ, BR 465, Km 47, CEP 23890-000, Seropédica - RJ, Brasil,

E-mail:sin-hueiwang@bol.com.br; tpimenta1@hotmail.com; glaucia_rural@yahoo.com.br;sam_piler@yahoo.com.br

${ }^{2}$ Embrapa Agroindústria de Alimentos, Av. das Américas, 29501, CEP 23020-470, Guaratiba, Rio de Janeiro - RJ, Brasil, E-mail: ascheri@ctaa.embrapa.br

${ }^{*}$ A quem a correspondência deve ser enviada 


\section{Material e métodos}

\subsection{Matéria-prima}

As matérias-primas usadas para os estudos foram: farinha de trigo, marca Lili, e grãos de soja (Glycine max (L.) Merril, cultivar BRS-155, safra de 2002), adquiridos em supermercado local e na Embrapa Soja (Londrina, PR), respectivamente.

\subsection{Métodos}

\section{Obtenção de farinha mista crua}

Os grãos de soja foram decorticados e branqueados, usando-se a metodologia de Wang et al. (2001). Em seguida, os mesmos grãos de soja foram misturados com a farinha de trigo, na proporção de 10:90 (base seca), sendo acrescentada a água, em dois níveis, em seguida as misturas foram desintegradas num moinho granulador de facas e martelos da marca Treu 7,5 CV modelo 112M989, com peneira de $2 \mathrm{~mm}$, obtendo-se farinhas mistas cruas de trigo e soja (90:10) com 32 e $35 \%$ de umidade, respectivamente.

\section{Composição centesimal aproximada}

$\mathrm{Na}$ farinha de trigo, nos grãos de soja integrais e decorticados, e na farinha mista crua de trigo e soja (90:10), foram realizadas as seguintes análises: umidade, extrato etéreo, proteína bruta e cinzas, segundo AACC (1995), e fibra bruta, conforme Kamer e Ginkel (1952).

\section{Processo de extrusão e fritura de pellets}

As farinhas mistas cruas de dois níveis de umidade foram extrusadas, respectivamente, em extrusor Brabender de rosca única, usando-se uma velocidade de alimentação constante de $1,2 \mathrm{~kg} / \mathrm{h}$, quatro velocidades de rotação de parafuso (VRP, No 5; $60,90,120$ e $150 \mathrm{rpm}$ ) e uma matriz de lâmina com espessura de $1 \mathrm{~mm}$. Os perfis de Temperatura de Barril (TB) do extrusor foram de $40{ }^{\circ} \mathrm{C}$ constante na zona 1 e de $60,70,80$ e $90{ }^{\circ} \mathrm{C}$ nas zonas 2 e 3 . Os produtos extrusados foram designados nas seguintes seqüências: $32 \%-60{ }^{\circ} \mathrm{C}, 32 \%-70{ }^{\circ} \mathrm{C}, 32 \%-80{ }^{\circ} \mathrm{C}$, $32 \%-90{ }^{\circ} \mathrm{C}, 35 \%-60{ }^{\circ} \mathrm{C}, 35 \%-70{ }^{\circ} \mathrm{C}, 35 \%-80{ }^{\circ} \mathrm{C}$ e $35 \%-90{ }^{\circ} \mathrm{C}$. Em seguida, os produtos extrusados foram cortados em tiras de 2 a $3 \mathrm{~cm}$ e secos em estufa a $50{ }^{\circ} \mathrm{C}$ com circulação de ar, durante 3 horas, obtendo-se, então, vários pellets extrusados de trigo e soja com aproximadamente 10 a $12 \%$ de umidade. Estes pellets foram mantidos durante uma semana em sacos plásticos à temperatura ambiente, para que fosse alcançado um equilíbrio de umidade entre os pellets. A fritura de pellets foi realizada à temperatura de $160{ }^{\circ} \mathrm{C}$ durante $4-5$ segundos, usando-se uma fritadeira comercial. Desta forma, foram obtidos pellets fritos (snacks de terceira geração) de trigo e soja.

\section{Índice de expansão (IE)}

O IE foi determinado, conforme Gimeno, Moraru e Kokini (2004), consistindo na relação entre o volume do pellet frito e o volume do pellet extrusado. Foram feitas 10 determinações em cada amostra.

\section{Índice de solubilidade em água (ISA)}

$\mathrm{Na}$ determinação de ISA, foram moídos os pellets secos no moinho Quadrumat Junior de rolo da marca Brabender Duisburg 342, com peneira de 0,25 mm, obtendo-se suas respectivas farinhas, sendo feita a determinação, segundo Anderson et al. (1969). Pesou-se 2,5 g de amostra num tubo de centrífuga e adicionou-se $30 \mathrm{~mL}$ de água destilada. Os conteúdos foram misturados num agitador por 30 minutos, em seguida centrifugou-se a amostra a $2.300 \mathrm{rpm}$ por 10 minutos. Esgotou-se o sobrenadante numa placa de petri previamente pesada. Secouse o sobrenadante a $100{ }^{\circ} \mathrm{C}$ por 3 horas, e determinaram-se os sólidos solúveis em água. O ISA foi calculado em relação a $100 \mathrm{~g}$ de amostra.

\section{Avaliação sensorial}

Antes da avaliação sensorial, os provadores foram selecionados e treinados previamente, conforme a metodologia usada por Fernandes et al. (2002). Foi avaliada a impressão global para os pellets fritos, produzidos com misturas de trigo e soja extrusadas, anteriormente, por diferentes VRP, a cada TB, em cada nível de umidade. Foram usadas a Escala Estruturada de 9 pontos ( 1 = extremamente ruim; $9=$ excelente $)$ e uma equipe de 10 provadores treinados. Para cada nível de umidade e para cada TB, foi selecionada apenas uma VRP, cuja amostra apresentasse a melhor impressão global.

Os pellets fritos selecionados anteriormente, foram submetidos ao teste sensorial de qualidade (aparência, sabor e textura), usando-se a Escala Estruturada de 9 pontos ( 1 = extremamente ruim; 9 = excelente) e uma equipe de 10 provadores treinados. $\mathrm{Na}$ avaliação, os atributos considerados em relação à aparência foram: cor e expansão; em relação à textura foram: dureza, fraturabilidade, mastigabilidade, adesividade e recobrimento na boca; e quanto ao sabor foram: sabor de feijão cru, adstringência e amargor. Foi assim selecionada a melhor TB para cada nível de umidade, que produzisse melhor qualidade sensorial, especialmente a textura. Da mesma maneira, foi selecionado o melhor nível de umidade que desse a melhor qualidade sensorial.

No pellet frito selecionado, foram acrescentados $1 \%$ de sal e $1 \%$ de saborizante (bacon ou queijo), sendo posteriormente submetidos ao teste massal de preferência, usando-se a Escala Hedônica de 9 pontos ( 1 = desgostei muitíssimo; 9 = gostei muitíssimo) e com 120 provadores não treinados.

\section{Análise estatística}

Para os resultados de análises químicas e físico-químicas, foi usado o Delineamento Inteiramente Casualizado (DIC), no qual foram feitas as análises de variância, com posterior comparação das diferenças entre médias pelo teste de Tukey a $5 \%$ de probabilidade. Nos testes sensoriais de impressão global e de qualidade (aparência, sabor e textura) com 4 amostras, foi usado o delineamento de blocos incompletos com 3 repetições. Nos testes sensoriais de qualidade (aparência, sabor e textura) e de preferência com 2 amostras, foi usado o delineamento de blocos casualizados. As diferenças estatísticas entre as amostras foram verificadas pela análise de variância e a comparação entre as médias, pelo teste de Tukey a $5 \%$ de probabilidade. Todas as 
análises estatísticas foram realizadas conforme os métodos descritos por Pimentel-Gomes (1991) e Cochran e Cox (1957).

\section{Resultados e discussão}

A composição centesimal aproximada, obtida da farinha de trigo (Tabela 1), foi semelhante à encontrada por Leitão, Gonçalves e Vitti (1989). O teor de cinzas dos grãos de soja decorticados foi semelhante, e os teores de proteína bruta e extrato etéreo foram maiores do que aqueles de grãos de soja integrais. O alto teor de fibra bruta da soja integral indica que a casca contém grande quantidade deste componente. A soja apresentou maiores teores de proteína bruta, extrato etéreo, cinzas e fibra bruta, do que a farinha de trigo. Uma vez que a soja não contém amido, a farinha mista crua de trigo e soja, na proporção 90:10, apresentou menor teor de carboidratos, em relação à farinha de trigo.

O Índice de Expansão (IE) dos pellets extrusados (Tabela 2) aumentou com o aumento da velocidade de rotação de parafuso (VRP, 60 a $150 \mathrm{rpm}$ ) na Temperatura de Barril (TB) de $60{ }^{\circ} \mathrm{C}$, nos dois níveis de umidades estudados (32 e 35\%). Entretanto, na TB de $70^{\circ} \mathrm{C}$, o máximo do IE foi verificado em $120 \mathrm{rpm}$ para $32 \%$ de umidade, e em $90 \mathrm{rpm}$ para $35 \%$ de umidade. Por outro lado, nas TB de 80 e $90^{\circ} \mathrm{C}$, o IE diminuiu com o aumento da VRP. Os pellets extrusados mostraram um aumento no IE com o aumento da TB até $80{ }^{\circ} \mathrm{C}$, exceto para umidade de $32 \%$ em $120 \mathrm{rpm}$, na qual o máximo do IE foi observado em $70^{\circ} \mathrm{C}$. Em TBs mais baixas $\left(60\right.$ e $70{ }^{\circ} \mathrm{C}$ ), os IE foram maiores para pellets extrusados com farinha mista de 35\% de umidade do que com aquela de $32 \%$ de umidade, mas, em TBs mais altas $\left(80\right.$ e $\left.90^{\circ} \mathrm{C}\right)$, ocorreu o contrário.

Amido é o componente geralmente responsável pela expansão. Ele é constituído por amilose (fração linear) e amilopectina (fração ramificada), as quais afetam a expansão distintamente. Os amidos ricos em amilopectina expandem mais do que os amidos ricos em amilose durante a extrusão, pois as cadeias lineares de amilose se alinham entre si na câmara de cisalhamento, dificultando a sua expansão (KOKINI; CHANG; LAI, 1992). Por outro lado, a expansão depende também da formação de uma matriz do amido, a qual induz à formação de vapores de água, resultando em bolhas (LAUNAY; LISCH, 1983). As matrizes da amilopectina não são tão duras quanto aquelas da amilose no mesmo conteúdo de umidade, o que pode diminuir a expansão (KOKINI; CHANG; LAI, 1992). Estudos de Chinnaswamy e Hanna (1988) levaram à conclusão de que deve existir uma proporção adequada de amilose e amilopectina para uma máxima expansão de amidos extrusados, o que indica a contribuição de ambas para esta expansão.

Lee et al. (2000) constataram que, o volume de expansão dos pellets de amido de milho extrusado, expandidos pelo aquecimento por microondas, correlacionou bem com o grau de gelatinização do amido. Sabe-se também que, o amido apresentou a temperatura de gelatinização relativamente alta em baixo conteúdo de umidade (BILIADERIS, 1992), e os tempos de residência em microondas para uma expansão não foram tão

Tabela 1. Composição centesimal aproximada (\% base seca) da farinha de trigo, dos grãos de soja integrais e decorticados, e da farinha mista crua de trigo e soja (90:10).

\begin{tabular}{lccrr}
\hline Composição (\%) & Farinha de trigo & Soja integral & Soja decorticada & Farinha mista crua de trigo e soja \\
\hline Proteína bruta & 13,06 & 42,04 & 45,90 & 16,08 \\
Extrato etéreo & 1,25 & 18,63 & 20,62 & 3,19 \\
Cinzas & 0,59 & 4,60 & 4,52 & 0,98 \\
Fibra bruta & 0,65 & 6,56 & 4,48 & 1,05 \\
Carboidratos $^{1}$ & 84,45 & 28,17 & 24,48 & 78,70 \\
\hline
\end{tabular}

${ }^{1}$ Calculado por diferença (100 - proteína - extrato etéreo - cinzas - fibra bruta)

Tabela 2. Índice de Expansão (IE) dos pellets de trigo e soja (90:10) extrusados por diferentes Velocidades de Rotação de Parafuso (VRP), em diferentes combinações de umidades e Temperaturas de Barril (TB) nas zonas 2 e $3^{1}$.

\begin{tabular}{|c|c|c|c|c|c|c|}
\hline \multirow[t]{2}{*}{ Identificação do pellet } & \multicolumn{4}{|c|}{ IE $(\%)^{2}$ dos pellets extrusados em diferentes VRP (rpm) } & \multirow[t]{2}{*}{ DMS } & \multirow[t]{2}{*}{$\mathrm{CV}$} \\
\hline & 60 & 90 & 120 & 150 & & \\
\hline $32 \%-60^{\circ} \mathrm{C}$ & $0,93^{\mathrm{dB}}$ & $1,01^{\mathrm{dB}}$ & $1,15^{\mathrm{dB}}$ & $1,95^{\mathrm{cA}}$ & 0,37 & 6,14 \\
\hline $32 \%-70{ }^{\circ} \mathrm{C}$ & $3,03^{\mathrm{cC}}$ & $5,14^{\mathrm{cB}}$ & $7,91^{\mathrm{aA}}$ & $2,98^{\mathrm{bC}}$ & 0,37 & 6,14 \\
\hline $32 \%-80{ }^{\circ} \mathrm{C}$ & $14,09^{\mathrm{aA}}$ & $8,74^{\mathrm{aB}}$ & $6,95^{\mathrm{bC}}$ & $6,39^{\mathrm{aD}}$ & 0,37 & 6,14 \\
\hline $32 \%-90{ }^{\circ} \mathrm{C}$ & $8,52^{\mathrm{bA}}$ & $7,14^{\mathrm{bB}}$ & $6,05^{\mathrm{cC}}$ & $2,83^{\mathrm{bD}}$ & 0,37 & 6,14 \\
\hline DMS & 0,37 & 0,37 & 0,37 & 0,37 & - & - \\
\hline CV (\%) & 6,14 & 6,14 & 6,14 & 6,14 & - & - \\
\hline $35 \%-60^{\circ} \mathrm{C}$ & $3,40^{c C}$ & $3,58^{\mathrm{bBC}}$ & $3,86^{\mathrm{cB}}$ & $4,59^{\mathrm{bA}}$ & 0,37 & 6,14 \\
\hline $35 \%-70{ }^{\circ} \mathrm{C}$ & $3,74^{\mathrm{cD}}$ & $8,02^{\mathrm{aA}}$ & $5,13^{\mathrm{bB}}$ & $4,63^{\mathrm{bC}}$ & 0,37 & 6,14 \\
\hline $35 \%-80^{\circ} \mathrm{C}$ & $10,72^{\mathrm{aA}}$ & $8,13^{\mathrm{aB}}$ & $6,84^{\mathrm{aC}}$ & $6,41^{\mathrm{aD}}$ & 0,37 & 6,14 \\
\hline $35 \%-90^{\circ} \mathrm{C}$ & $4,52^{\mathrm{bA}}$ & $3,53^{\mathrm{bB}}$ & $2,38^{\mathrm{dC}}$ & $1,54^{\mathrm{CD}}$ & 0,37 & 6,14 \\
\hline DMS & 0,37 & 0,37 & 0,37 & 0,37 & - & - \\
\hline CV (\%) & 6,14 & 6,14 & 6,14 & 6,14 & - & - \\
\hline
\end{tabular}

${ }^{1}$ Temperatura do extrusor na zona $1: 40{ }^{\circ} \mathrm{C}$ (constante); $\mathrm{e}^{2}$ as médias seguidas de letras diferentes, maiúsculas nas linhas e minúsculas nas colunas, diferem estatisticamente entre si pelo teste de Tukey a $5 \%$ de probabilidade (DMS = diferença mínima significativa; e CV = coeficiente de variação). 
longos e suficientes para permitir uma completa gelatinização, desta forma uma gelatinização do amido por extrusão, antes de sua expansão por microondas, foi considerada benéfica (WANG et al., 1991). A expansão máxima dos pellets foi observada quando houve uma gelatinização do amido em torno de 50\% (LEE et al., 2000), justificando-se todos os resultados encontrados no presente trabalho.

O fato de que o IE aumentou com o aumento da VRP e da TB, apenas até certo ponto (Tabela 2), pode ser explicado a seguir. O aumento da VRP resultou, no processo de extrusão, em maior atrito entre as moléculas, gerando maior calor, o que por conseqüência pode ter favorecido a gelatinização do amido. Entretanto, um excesso de calor, gerado por aumento da VRP, pode também ter causado uma hidrólise do amido (WANG et al., 2006). Em baixas temperaturas, os materiais crus se tornaram mais viscosos, resultando em menor expansão de produtos, enquanto que em altas temperaturas, uma dextrinização excessiva juntamente com uma estrutura enfraquecida podem também ter resultado numa expansão reduzida desses produtos (CHEN et al., 1991).

O Índice de Solubilidade em Água (ISA) dos pellets extrusados (Tabela 3) aumentou com o aumento da VRP (60 a 150 pm) em todas as TBs $\left(60\right.$ a $\left.90^{\circ} \mathrm{C}\right)$ e umidades $(32$ e $35 \%)$ estudadas, exceto para a TB de $90^{\circ} \mathrm{C}$ na umidade de $32 \%$, na qual ocorreu o contrário. E para a mesma VRP, o aumento da TB resultou também num aumento do ISA na umidade de $35 \%$, entretanto, na umidade de $32 \%$ o aumento do ISA foi apenas até $80^{\circ} \mathrm{C}$, exceto para VRP de $150 \mathrm{rpm}$, na qual não houve aumento até $70^{\circ} \mathrm{C}$, e depois de $70^{\circ} \mathrm{C}$ ocorreu um decréscimo. Os valores do ISA foram maiores para a umidade de $35 \%$ do que para a de $32 \%$. Resultados semelhantes foram encontrados por Carvalho, Ascheri e Cal-Vidal (2002), os quais constataram que houve um aumento no ISA a altas temperaturas. O ISA aumentou quando a umidade variou de 27 a $33 \%$, à temperatura acima de $75^{\circ} \mathrm{C}$. Porém, com uma umidade de $43 \%$, o ISA diminuiu.

O valor de ISA foi tomado como indicativo da degradação sucessiva do amido, como conseqüência do tratamento sofrido no extrusor. Os valores elevados de ISA corresponderam às misturas dextrinizadas, e o aumento do mesmo foi observado nas amostras gelatinizadas e dextrinizadas (GUTIÉRREZ; GÓMEZ, 1987).

Além da fragmentação do amido, o conteúdo de proteína pode também afetar o ISA. A desnaturação e a insolubilização da fração protéica, nas misturas de milho com frações protéicas de leguminosas e com o aumento da temperatura do extrusor, diminuíram o seu ISA (GUJSKA; KHAN, 1991). Por outro lado, o ISA das misturas extrusadas de arroz e soja aumentou nitidamente depois da adição de farinha de soja desengordurada, resultado atribuído ao alto teor de proteínas solúveis da soja (CHAUHAN; BAINS, 1985).

Considerando-se que as matérias-primas usadas no presente trabalho foram o trigo e a soja, é possível que, além do amido, as proteínas estejam também afetando o seu ISA. O aumento do ISA se deve, provavelmente, à fragmentação, tanto do amido gelatinizado quanto da proteína desnaturada, aumentando a quantidade de sólidos solúveis presentes. No entanto, deve-se levar em conta que a degradação do amido e a desnaturação da proteína podem também favorecer a reação de Maillard que, por conseqüência, propicia a formação de agregado de alto peso molecular, diminuindo o ISA.

A Tabela 4 apresenta médias dos escores da avaliação sensorial de impressão global dos pellets fritos, preparados com farinhas de trigo e soja (90:10) extrusadas, por diferentes VRPs, em diferentes combinações de umidade e TBs nas zonas 2 e 3. Pode-se verificar, que os pellets fritos mostraram melhores impressões globais com o aumento da VRP (60 a $150 \mathrm{rpm}$ ) até certo ponto, o qual variou conforme a TB $\left(60\right.$ a $\left.90^{\circ} \mathrm{C}\right)$ e a umidade (32 e 35\%) usadas. Em TBs mais baixas, necessitou-se uma VRP maior para obter produtos com melhores impressões globais, enquanto que em TBs mais altas, uma menor VRP foi suficiente. De todos os níveis de umidades estudados, a TB de $80^{\circ} \mathrm{C}$ foi a que produziu pellets fritos (Tabela 5) com melhor aparência, sabor e textura. O pellet frito (Tabela 6), preparado com a farinha mista com $32 \%$ de umidade e extrusada em $60 \mathrm{rpm}$ a $80^{\circ} \mathrm{C}$, apresentou escores de aparência e textura maiores do que aquele preparado com $35 \%$ de umidade, embora não tenha

Tabela 3. Índice de Solubilidade em Água (ISA) dos pellets de trigo e soja (90:10) extrusados por diferentes Velocidades de Rotação de Parafuso (VRP), em diferentes combinações de umidades e Temperaturas de Barril (TB) nas zonas 2 e $3^{1}$.

\begin{tabular}{|c|c|c|c|c|c|c|}
\hline \multirow[t]{2}{*}{ Identificação do pellet } & \multicolumn{4}{|c|}{ ISA $(\%)^{2}$ dos pellets extrusados em diferentes VRP (rpm) } & \multirow[t]{2}{*}{ DMS } & \multirow[t]{2}{*}{$\mathrm{CV}$} \\
\hline & 60 & 90 & 120 & 150 & & \\
\hline $32 \%-60{ }^{\circ} \mathrm{C}$ & $9,37^{\mathrm{cD}}$ & $11,74^{\mathrm{cC}}$ & $14,10^{\mathrm{cB}}$ & $16,61^{\mathrm{aA}}$ & 1,12 & 2,76 \\
\hline $32 \%-70{ }^{\circ} \mathrm{C}$ & $11,02^{\mathrm{bD}}$ & $13,48^{\mathrm{bC}}$ & $15,38^{\mathrm{bB}}$ & $17,05^{\mathrm{aA}}$ & 1,12 & 2,76 \\
\hline $32 \%-90^{\circ} \mathrm{C}$ & $14,00^{\mathrm{aA}}$ & $12,65^{\mathrm{bcB}}$ & $11,68^{\mathrm{dC}}$ & $10,09^{\mathrm{bD}}$ & 1,12 & 2,76 \\
\hline DMS & 1,12 & 1,12 & 1,12 & 1,12 & - & - \\
\hline $35 \%-70{ }^{\circ} \mathrm{C}$ & $11,14^{\mathrm{cD}}$ & $15,20^{\mathrm{bC}}$ & $17,50^{\mathrm{bB}}$ & $18,87^{\mathrm{bcA}}$ & 1,12 & 2,76 \\
\hline $35 \%-80^{\circ} \mathrm{C}$ & $13,09^{\mathrm{bD}}$ & $16,31^{\mathrm{abC}}$ & $18,04^{\mathrm{bB}}$ & $19,73^{\mathrm{abA}}$ & 1,12 & 2,76 \\
\hline $35 \%-90{ }^{\circ} \mathrm{C}$ & $14,37^{\mathrm{aD}}$ & $17,13^{\mathrm{aC}}$ & $19,52^{\mathrm{aB}}$ & $20,68^{\mathrm{aA}}$ & 1,12 & 2,76 \\
\hline DMS & 1,12 & 1,12 & 1,12 & 1,12 & - & - \\
\hline CV(\%) & 2,76 & 2,76 & 2,76 & 2,76 & - & - \\
\hline
\end{tabular}

${ }^{1}$ Temperatura do extrusor na zona $1: 40^{\circ} \mathrm{C}$ (constante); $\mathrm{e}^{2}$ as médias seguidas de letras diferentes, maiúsculas nas linhas e minúsculas nas colunas, diferem estatisticamente entre si pelo teste de Tukey a 5\% de probabilidade (DMS = diferença mínima significativa; e CV = coeficiente de variação). 
Tabela 4. Médias dos escores da avaliação sensorial de impressão global dos pellets fritos, preparados com farinhas de trigo e soja (90:10) extrusadas, por diferentes Velocidades de Rotação de Parafuso (VRP), em diferentes combinações de umidades e Temperaturas de Barril (TB) nas zonas 2 e $3^{1}$.

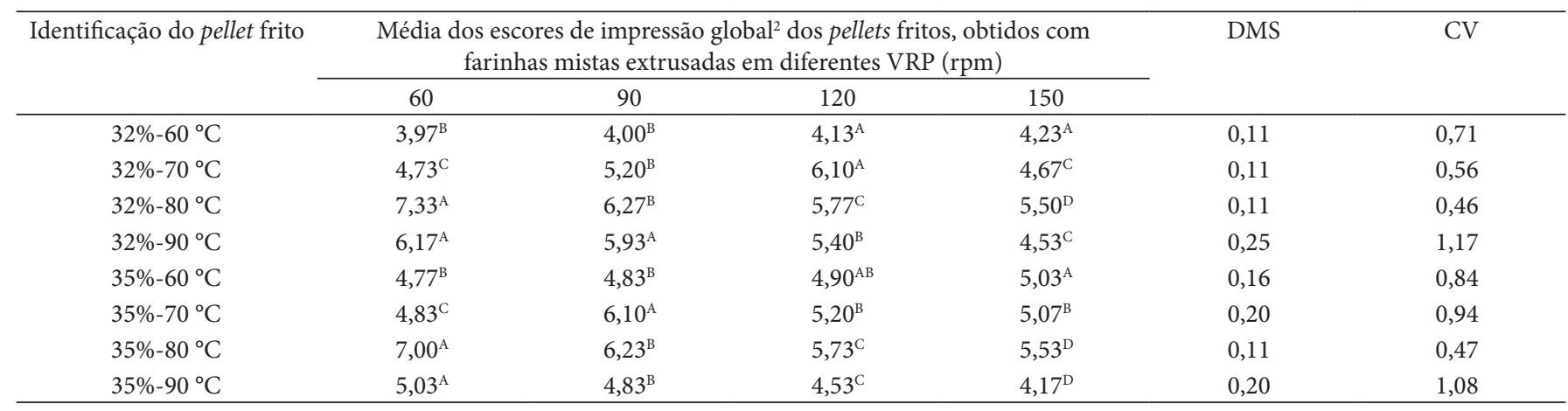

${ }^{1}$ Temperatura do extrusor na zona $1: 40{ }^{\circ} \mathrm{C}$ (constante); $\mathrm{e}^{2}$ as médias, na mesma linha, seguidas de letras diferentes, diferem estatisticamente entre si pelo teste de Tukey a $5 \%$ de probabilidade (DMS = diferença mínima significativa; e CV = coeficiente de variação).

Tabela 5. Média dos escores da avaliação sensorial de aparência, sabor e textura para pellets fritos, preparados com farinhas de trigo e soja (90:10) extrusadas, em Ótimas Velocidades de Rotação de Parafuso (OVRP) e diferentes combinações de umidades e Temperaturas de Barril (TB) nas zonas 2 e $3^{1}$.

\begin{tabular}{lcccc}
\hline $\begin{array}{c}\text { Identificação do } \\
\text { pellet frito }\end{array}$ & $\begin{array}{c}\text { OVRP } \\
(\mathrm{rpm})\end{array}$ & \multicolumn{3}{c}{ Média dos escores de avaliação } \\
\cline { 3 - 5 } & & Aparência & Sabor & Textura \\
\hline $32 \%-60^{\circ} \mathrm{C}$ & 150 & $5,33^{\mathrm{c}}$ & $6,03^{\mathrm{c}}$ & $3,87^{\mathrm{d}}$ \\
$32 \%-70^{\circ} \mathrm{C}$ & 120 & $5,93^{\mathrm{bc}}$ & $6,47^{\mathrm{b}}$ & $5,97^{\mathrm{c}}$ \\
$32 \%-80^{\circ} \mathrm{C}$ & 60 & $8,47^{\mathrm{a}}$ & $7,07^{\mathrm{a}}$ & $7,53^{\mathrm{a}}$ \\
$32 \%-90^{\circ} \mathrm{C}$ & 60 & $6,23^{\mathrm{b}}$ & $6,37^{\mathrm{b}}$ & $6,03^{\mathrm{b}}$ \\
$\mathrm{DMS}$ & - & 0,65 & 0,30 & 0,03 \\
$\mathrm{CV}(\%)$ & - & 2,57 & 1,18 & 1,07 \\
$35 \%-60^{\circ} \mathrm{C}$ & 150 & $5,47^{\mathrm{d}}$ & $6,07^{\mathrm{d}}$ & $4,03^{\mathrm{d}}$ \\
$35 \%-70^{\circ} \mathrm{C}$ & 90 & $6,00^{\mathrm{b}}$ & $6,53^{\mathrm{b}}$ & $6,03^{\mathrm{b}}$ \\
$35 \%-80^{\circ} \mathrm{C}$ & 60 & $8,13^{\mathrm{a}}$ & $6,97^{\mathrm{a}}$ & $7,10^{\mathrm{a}}$ \\
$35 \%-90^{\circ} \mathrm{C}$ & 60 & $5,67^{\mathrm{c}}$ & $6,20^{\mathrm{c}}$ & $5,67^{\mathrm{c}}$ \\
$\mathrm{DMS}$ & - & 0,20 & 0,11 & 0,20 \\
$\mathrm{CV}(\%)$ & - & 0,79 & 0,45 & 0,87 \\
\hline
\end{tabular}

${ }^{1}$ Temperatura do extrusor na zona $1: 40^{\circ} \mathrm{C}$ (constante); ${ }^{2}$ as médias, na mesma coluna, seguidas de letras diferentes, diferem estatisticamente entre si pelo teste de Tukey a $5 \%$ de probabilidade $(\mathrm{DMS}$ = diferença mínima significativa; e $\mathrm{CV}$ = coeficiente de variação).

Tabela 6. Médias dos escores da avaliação sensorial de aparência, sabor e textura para pellets fritos, preparados com farinhas de trigo e soja (90:10) extrusadas, em dois níveis de umidades, por suas respectivas Ótimas Temperaturas de Barril (OTB) nas zonas 2 e $3^{1}$ e Ótimas Velocidades de Rotação de Parafuso (OVRP).

\begin{tabular}{lccccc}
\hline Identificação do & OTB & OVRP & \multicolumn{3}{c}{ Média dos escores de avaliação } \\
\cline { 2 - 6 } \multicolumn{1}{c}{ pellet frito } & $\left({ }^{\circ} \mathrm{C}\right)$ & $(\mathrm{rpm})$ & Aparência & Sabor & Textura \\
\hline $32 \%-80{ }^{\circ} \mathrm{C}$ & 80 & 60 & $8,52^{\mathrm{a}}$ & $7,05^{\mathrm{a}}$ & $7,55^{\mathrm{a}}$ \\
$35 \%-80{ }^{\circ} \mathrm{C}$ & 80 & 60 & $8,20^{\mathrm{b}}$ & $6,95^{\mathrm{a}}$ & $7,15^{\mathrm{b}}$ \\
$\mathrm{DMS}$ & - & - & 0,30 & 0,14 & 0,29 \\
$\mathrm{CV}(\%)$ & - & - & 5,64 & 3,24 & 6,08
\end{tabular}

${ }^{1}$ Temperatura do extrusor na zona 1: $40^{\circ} \mathrm{C}$ (constante); $\mathrm{e}^{2}$ As médias, na mesma coluna, seguidas de letras diferentes, diferem estatisticamente entre si pelo teste de Tukey a $5 \%$ de probabilidade (DMS = diferença mínima significativa; e CV = coeficiente de variação).

tido diferenças significativas no sabor entre as duas umidades estudadas. Não houve diferença significativa em relação à preferência (Tabela 7) nos pellets fritos de melhores qualidades sensoriais, saborizados com bacon ou com queijo.
Tabela 7. Preferência pelos pellets fritos de diferentes sabores, preparados com a mesma farinha de trigo e soja (90:10) extrusada, em ótima umidade $(32 \%)$, ótima temperatura de barril $\left(80^{\circ} \mathrm{C}\right)$ nas zonas 2 e $3^{1}$ e em ótima velocidade de rotação de parafuso $(60 \mathrm{rpm})$.

\begin{tabular}{lcc}
\hline $\begin{array}{c}\text { Identificação do } \\
\text { pellet frito }\end{array}$ & Saborizante & Preferência $^{2}$ \\
\hline $32 \%-80^{\circ} \mathrm{C}-60 \mathrm{rpm}$ & Bacon & $8,16^{\mathrm{a}}$ \\
$32 \%-80^{\circ} \mathrm{C}-60 \mathrm{rpm}$ & Queijo & $8,04^{\mathrm{a}}$ \\
$\mathrm{DMS}$ & - & 0,18 \\
$\mathrm{CV}(\%)$ & - & 8,92 \\
\hline
\end{tabular}

${ }^{1}$ Temperatura do extrusor na zona $1: 40^{\circ} \mathrm{C}$ (constante); e ${ }^{2}$ as médias, na mesma coluna, seguidas de letras diferentes, diferem estatisticamente entre si pelo teste de Tukey a $5 \%$ de probabilidade (DMS = diferença mínima significativa; e $\mathrm{CV}=$ coeficiente de variação).

Comparando-se os resultados das análises sensoriais e os do IE (Tabelas 2, 4, 5 e 6), observa-se que, os pellets fritos com as melhores características sensoriais foram aqueles que tiveram maiores valores de IE. Os valores altos de IE dos pellets são indicativos de melhores características sensoriais.

Além da expansão, acredita-se que a cor tenha também contribuído para a aparência dos pellets fritos. Em relação à textura, Chen et al. (1991) verificaram que a TB teve efeito significativo sobre a crocância e a mastigabilidade dos extrusados de milho. A crocância se correlacionou com a expansão. Um aumento da TB resultou em aumento da expansão, obtendo-se um produto com maior crocância e mais fácil de ser mastigado.

\section{Conclusões}

- O Índice de Expansão (IE) dos pellets extrusados, obtidos com mistura de trigo e soja (90:10), aumentou com o aumento da velocidade de rotação de parafuso (VRP, 60 a $150 \mathrm{rpm}$ ) e da temperatura de barril (TB, 60 a $90{ }^{\circ} \mathrm{C}$ ) até certo ponto, depois do qual passou a diminuir. Em TBs mais baixas $\left(60\right.$ e $70{ }^{\circ} \mathrm{C}$ ), os IEs foram maiores para pellets extrusados com farinha mista de $35 \%$ de umidade do que com aquela de $32 \%$ de umidade, porém, em TBs mais altas $\left(80\right.$ e $\left.90{ }^{\circ} \mathrm{C}\right)$ ocorreu o contrário;

- O aumento da VRP resultou num aumento do Índice de Solubilidade em Água (ISA) das farinhas de pellets extrusados, exceto para a $\mathrm{TB}$ de $90{ }^{\circ} \mathrm{C}$ na umidade de 
32\%. E para a mesma VRP, o ISA aumentou também com o aumento da TB na umidade de $35 \%$, entretanto, na umidade de $32 \%$ este aumento só foi até $80{ }^{\circ} \mathrm{C}$, exceto para VRP de $150 \mathrm{rpm}$. Os valores do ISA foram maiores para a umidade de $35 \%$ do que para a de $32 \%$; e

- O pellet frito, preparado com a farinha de trigo e soja (90:10) com 32\% de umidade e extrusada em $60 \mathrm{rpm}$ a $80{ }^{\circ} \mathrm{C}$, apresentou a melhor aparência e textura, sendo preferido pela equipe de provadores não treinados, tanto com sabor de bacon como com sabor de queijo.

\section{Agradecimentos}

Ao CNPq pela concessão de Bolsa de PQ à primeira autora e Bolsa de PIBIC -UFRRJ à segunda autora.

\section{Referências bibliográficas}

AACC - AMERICAN ASSOCIATION OF CEREAL CHEMISTS. Approved methods of the American Association of Cereal Chemists. 9 ed. St Paul: AACC, 1995. 2v.

ANDERSON, R. A. et al. Gelatinization of corn grits by roll-and extrusion-cooking. Cereal Science Today, v. 14, n. 1, p. 4-12, 1969.

BILIADERIS, C. G. Structures and phase transitions of starch in food systems. Food Technology, v. 46, n. 1, p. 98-109, 1992.

CABALLERO-CÓRDOBA, G. M.; WANG, S. H.; SGARBIERI, V. C. Características nutricionais e sensoriais de sopa cremosa semiinstantânea à base de farinhas de trigo e soja desengordurada. Pesquisa Agropecuária Brasileira, v. 29, n. 7, p. 1137-1143, 1994.

CARVALHO, R. V.; ASCHERI, J. L. R.; CAL-VIDAL, J. Efeito dos parâmetros de extrusão nas propriedades físicas de pellets $(3 \mathrm{G})$ de misturas de farinhas de trigo, arroz e banana. Ciência e Agrotecnologia, v. 26, n. 5, p. 1006-1018, 2002.

CHAUHAN, G. S.; BAINS, G. S. Effect of defatted soy flour on the physico-chemical characteristics of extruded rice products. Journal of Food Science and Technology, v. 22, n. 2, p. 115-118, 1985.

CHEN, J. et al. Effects of extrusion conditions on sensory properties of corn meal extrudates. Journal of Food Science, v. 56, n. 1, p. 84-89, 1991.

CHINNASWAMY, R.; HANNA, M. A. Relationship between amylase content and extrusion-expansion properties of corn starches. Cereal Chemistry, v. 65, n. 2, p. 138-143, 1988.

COCHRAN, W. G.; COX, G. M. Experimental designs. 2 ed. New York: John Wiley, 1957.611p.
FERNANDES, M. S. et al. Produtos extrusados expandidos de misturas de canjiquinha e soja para uso como petiscos. Pesquisa Agropecuária Brasileira, v. 37, n. 10, p. 1495-1501, 2002.

GIMENO, E.; MORARU, C. I.; KOKINI, J. L. Effect of xanthan gum and $\mathrm{CMC}$ on the structure and texture of corn flour pellets expanded by microwave heating. Cereal Chemistry, v. 81, n. 1, p. 100-107, 2004

GUJSKA, E.; KHAN, K. Functional properties of extrudates from high starch fractions of navy and pinto beans and corn meal blended with legume high protein fractions. Journal of Food Science, v. 56, n. 2, p. 431-435, 1991.

GUTIÉRREZ, M. V. G.; GÓMEZ, M. H. Modelo para la extrusión de mezclas maíz: soya (70:30). Archivos Latinoamericanos de Nutrición, v. 37, n. 3, p. 494-502, 1987.

KAMER, J. H. VAN De; GINKEL, L. VAN. Rapid determination of crude fiber in cereals. Cereal Chemistry, v. 29, n. 4, p. 239-251, 1952.

KOKINI, J. L.; CHANG, C. N.; LAI, L. S. The role of rheological properties on extrudate expansion. In: KOKINI, J. L.; HO, C. T.; KARWE, M. V. Food Extrusion Science and Technology. New York: Marcel Deckker, 1992. p. 631-653.

LAUNAY, B.; LISCH, J. M. Twin-screw extrusion cooking of starch: behavior of starch pastes, expansion and mechanical properties of extrudates. Journal of Food Engineering, v. 2, n. 3, p. 259-280, 1983.

LEE, E. Y. et al. Effects of gelatinization and moisture content of extruded starch pellets on morphology and physical properties of microwave expanded products. Cereal Chemistry, v. 77, n. 7, p. 769-773, 2000.

LEITÃO, R. F. F.; GONÇALVES, J. R.; VITTI, P. Utilização da alta temperatura na secagem de macarrão. Coletânea Ital, v. 19, n. 2, p. 186-195, 1989.

MERCIER, C. et al. Formation of amylose-lipid complexes by twinscrew extrusion cooking of manioc starch. Cereal Chemistry, v. 57, n. 1, p. 4-9, 1980.

OWUSU-ANSAH, J.; VAN De VOORT, F. R.; STANLEY, D. W. Physicochemical changes in cornstarch as a function of extrusion variables. Cereal Chemistry, v. 60, n. 4, p. 319-324, 1983.

PIMENTEL GOMES, F. Curso de estatística experimental. 13 ed. São Paulo: Nobel, 1991. 468p.

WANG, S. H. et al. Características tecnológicas y sensoriales de harinas de arroz-soya (70:30) extruídas para uso como papilla instantánea. Alimentaria, v. 38, n. 324, p. 77-84, 2001.

WANG, S. H. et al. Absorção de água e propriedades espumantes de farinhas extrusadas de trigo e soja. Ciência e Tecnologia de Alimentos, v. 26, n. 2, p. 475-481, 2006.

WANG, S. S. et al. Experimental analysis and computer simulation of starch-water interaction during phase transition. Journal of Food Science, v. 56, n. 1, p. 121-124, 1991. 